\title{
RELAÇÃO ENTRE AS PRÁTICAS DO BOARD INTERLOCKING E CARACTERÍSTICAS DE EMPRESAS DE ESTRUTURA DE PROPRIEDADE FAMILIAR COM AÇÕES MAIS NEGOCIADAS NA BM\&FBOVESPA
}

\section{1- Ilse Maria Beuren}

Doutora em Controladoria e Contabilidade pela Faculdade de Economia e Administração da Universidade de São Paulo (FEA/USP), Brasil.

Professora do Programa de Pós-Graduação em Ciências Contábeis da Universidade Federal do Paraná (UFPR), Brasil. ilse.beuren@gmail.com

http://lattes.cnpq.br/4514517594315817

\section{2- Andréia Carpes Dani}

Mestre em Ciências Contábeis pela Universidade Regional de Blumenau (FURB), Brasil. andreiacarpesd@yahoo.com

http://lattes.cnpq.br/1178450971204407

\section{3- Franciele Beck}

Mestre em Ciências Contábeis pela Universidade Regional de Blumenau (FURB), Brasil. beck.franciele@gmail.com

http://lattes.cnpq.br/8409984011279149

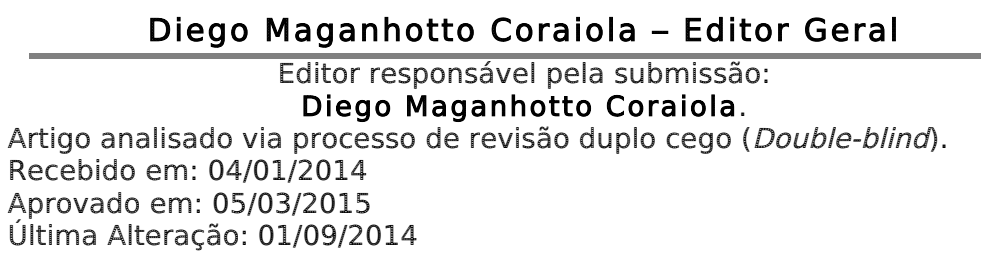

* Contato Principal: Av. Prefeito Lothário Meissner, 632, Campus III. Jardim Botânico, Curitiba/PR, Brasil. CEP: 80210-070. 


\section{RELAÇÃO ENTRE AS PRÁTICAS DO BOARD INTERLOCKING E CARACTERÍSTICAS DE EMPRESAS DE ESTRUTURA DE PROPRIEDADE FAMILIAR COM AÇÕES MAIS NEGOCIADAS NA BM\&FBOVESPA}

\section{RESUMO}

O estudo objetiva verificar a relação entre as práticas do Board Interlocking e características de empresas de estrutura de propriedade familiar com ações mais negociadas na BM\&FBovespa. Estudo descritivo foi realizado por meio de pesquisa documental, com abordagem quantitativa. Coletaram-se informações nos relatórios financeiros das 23 empresas brasileiras de capital aberto com estrutura e propriedade familiar, classificadas pela Revista Capital Aberto. Os resultados apontam que a prática do Board Interlocking ocorreu em $57 \%$ das empresas da amostra, indicando ser uma prática comum. Evidenciam também uma relação significativa entre as variáveis prática do Board Interlocking e características de propriedade e controle familiar. Conclui-se que a prática do Board Interlocking pelos membros do conselho de administração, diretoria e conselho fiscal é adotada nas empresas pesquisadas, apesar da tendência da estrutura de propriedade familiar ser mais concentrada.

\section{Palavras-Chave}

Board Interlocking. Estrutura de propriedade. Empresas familiares.

\section{RELATIONSHIP BETWEEN BOARD INTERLOCKING PRACTICES AND BUSINESS CHARACTERISTICS OF FAMILY OWNERSHIP STRUCTURE WITH MORE STOCKS TRADED IN BM\&FBOVESPA}

\section{ABSTRACT}

The goal of this study is to investigate the relationship between the Board Interlocking practices and business characteristics of family ownership structure which have more stocks traded in BM\&FBovespa. Study descriptive being conducted through desk research, with a quantitative approach. The information was collected from the financial reports of 23 Brazilian open capital companies of family ownership structure, classified by the Open Capital Magazine. The results show that the Board Interlocking practice occurred in $57 \%$ of the companies in the sample, indicating that it is a common practice. Show also a significant relationship between the variables Board Interlocking practices and characteristics of family ownership structure and control, with a canonical correlation of $83 \%$ and a canonical R of $69 \%$. It is concluded that the Interlocking Board practices by members of the board of directors, directors and supervisory board is adopted in the surveyed companies, despite the tendency of family ownership structure be more concentrated.

\section{Keywords}

Board Interlocking. Ownership structure. Family businesses. 
Relação entre as práticas do board interlocking e características de empresas de estrutura de propriedade familiar com ações mais negociadas na BM\&FBOVESPA

\section{Introdução}

O papel desempenhado pelo conselho de administração tem sido um dos aspectos atualmente bastante considerado e questionado no ambiente corporativo. Observa-se que fatores como as relações sociais e institucionais estão cada vez mais interligados, por originarem-se da atuação dos membros dos conselhos das grandes companhias (Mendes-da-Silva, Rossoni, Martin, \& Martelanc, 2008). Considera-se que esse fato também esteja relacionado com a estrutura de propriedade e seu tipo de controle.

Santos e Silveira (2007) verificaram que a prática de relações sociais e institucionais tem predominância na estrutura de propriedade difusa. Uma das questões associadas à eficácia dos conselheiros e funcionamento do conselho de administração das empresas trata do fenômeno de participação cruzada dos conselheiros em outras companhias. "Esta prática, denominada Board Interlocking, estabelece uma união entre diferentes empresas por meio da presença de conselheiros em comum em seus conselhos" (Santos, \& Silveira, 2007, p. 158).

Segundo Mendes-da-Silva e Vidal (2010), a prática do interlocking reflete a estratificação no ambiente corporativo no Brasil e está associada com o desempenho do conselho durante sua prática gerencial. Para os autores, isso se deve ao recente desenvolvimento do mercado de capitais brasileiro, que num cenário anterior era concentrado em alguns membros do conselho tradicional.

Existem diversas pesquisas que buscam relacionar a prática do Board Interlocking com diferentes fatores determinantes e demais elementos relacionados. Dentre estas destacam-se os estudos de Mizruchi (1996) sobre os determinantes e influencias da prática do interlocking para as companhias; Non e Franses (2007) que relacionaram o interlocking ao desempenho das empresas; Heng e Gygax (2009) que investigaram a relação entre o interlocking com os planos de compensação dos executivos (membros) das empresas.

A partir dessas pesquisas sobre a prática do Board Interlocking, busca-se, diferentemente desses estudos anteriores, expandir a discussão sobre o tema no contexto corporativo brasileiro, especificamente em empresas de capital aberto que adotam práticas de governança corporativa e que possuem estrutura de propriedade e controle familiar.

Tendo em vista as considerações delineadas, este estudo apresenta a seguinte questão de pesquisa: Qual a relação entre as práticas do Board Interlocking e características de empresas de estrutura de propriedade e controle familiar com ações mais negociadas na BM\&FBovespa? Nesse sentido objetiva-se verificar a relação entre as práticas do Board Interlocking e características de empresas de estrutura de propriedade familiar com ações mais negociadas na BM\&FBovespa.

O estudo justifica-se pelo fato da prática de Board Interlocking ser um assunto pouco difundido e pesquisado no âmbito acadêmico, e que pode trazer importantes contribuições no sentido da caracterização do perfil das empresas brasileiras a esse respeito. Esta pesquisa amplia a discussão sobre a prática do Board Intelocking pelas companhias brasileiras, considerando que em âmbito nacional foram identificados apenas os estudos de Santos e Silveira (2007), Mendes-da-Silva, Rossoni, Martin e Martelanc (2008) e de Mendes-da-Silva (2010). Trata-se de pesquisas pioneiras no estudo exploratório desta temática no país.

Santos e Silveira (2007) constataram na pesquisa realizada em empresas brasileiras que a prática do Board Interlocking é frequente e está associada as empresas de grande porte, com controle disperso e grandes conselhos. Assim pretende-se contribuir ao investigar o tema sob o prisma das empresas de controle concentrado, especificamente as familiares. $O$ interesse em verificar esta prática em empresas de propriedade familiar decorre do fato de apresentarem importante participação na economia brasileira, e ao contrário das empresas de controle pulverizado, possuem maior concentração de controle.

Considera-se relevante também o estudo da prática do Board Interlocking sob o ponto de vista social, uma vez que esta é uma prática frequente das empresas brasileiras (Santos, \& Silveira, 2007, Mendes-da-Silva, 2010). Identificar a configuração da prática do Board Interlocking e as características associadas de empresas familiares pode revelar aspectos importantes para a caracterização e desenvolvimento do mercado de capitais brasileiro.

$\mathrm{O}$ estudo está dividido em cinco seções. Além da primeira, que traz a introdução, apresenta-se na sequência o tópico da fundamentação teórica. Em seguida evidenciam-se os aspectos metodológicos da pesquisa. Após, apresenta-se a descrição e análise dos resultados e, por fim, as conclusões da pesquisa. 


\section{Fundamentação Teórica}

\subsection{Estrutura de Propriedade}

O retrospecto das pesquisas iniciais sobre estrutura de propriedade aponta com destaque o estudo de Adam Smith. Berle e Means (1984) destacaram a separação entre propriedade e controle, e Jensen e Meckling (1976) integraram elementos da teoria da agência, teoria dos direitos de propriedade e teoria das finanças para desenvolver uma teoria da estrutura de propriedade e controle da empresa.

Na concepção de que a origem das sociedades anônimas se deu por meio de grupos de investidores que associavam contribuições de capital e de risco para manter um empreendimento, tem-se que a escassez de riquezas é um fator que influencia à pulverização da propriedade das empresas (Berle, \& Means, 1984, p. 9).

Jensen e Meckling (1976, p. 9) apresentam que a corporação privada ou firma é uma ficção legal que serve como coerência para a contratação de relacionamentos, também caracterizada pela existência de crédito residual divisível sobre os ativos e fluxos de caixa da organização. Este entendimento remete ao capital social das sociedades anônimas, composto por ações que podem ser ordinárias, preferenciais ou de fruição, as quais integram a estrutura de propriedade das empresas.

Kang e Sorensen (1999, p. 8) apresentam que a propriedade é um complexo fenômeno econômico e sociológico que ocorre em um contexto legal, e cria incentivos e oportunidades para capturar os direitos de propriedade, além de empreender ações que influenciam no desempenho da empresa.

As proporções cada vez maiores de sociedades anônimas e seu constante crescimento no mercado proporcionaram mudanças significativas no conceito de propriedade, separando "a pessoa do proprietário e usufrutuário, da pessoa do administrador da empresa" (Berle, \& Means, 1984, p. 12). A separação entre propriedade, pulverizada entre muitos acionistas, e o controle, exercido por diretores e ou grupo de pessoas, que, no máximo, possuiriam uma pequena fração do capital da empresa, é um ponto central da empresa moderna, e um campo aberto de questões e temáticas para o ambiente acadêmico.

No Brasil, pesquisadores vêm investigando esta temática em empresas. Dami, Rogers e Ribeiro (2007) verificaram se existem diferenças de rentabilidade, valor de mercado, estrutura de capital, risco e tamanho do ativo em relação ao grau de concentração acionária de empresas brasileiras nãofinanceiras listadas na Bovespa entre 1997 a 2001. O estudo apontou que em ambientes instáveis há maior concentração de propriedade pela relação encontrada entre performance e concentração acionária.

La Porta, Lopez-de-Silanes e Shleifer (1998, p. 10) consideraram como propriedade e controle apenas as ações com direito a voto (ordinárias), não as que representam direito ao fluxo de caixa (preferenciais). A partir desta distinção, os autores apresentaram duas modalidades de estrutura: dispersa (em que não há um acionista controlador), e concentrada (controle exercido por um indivíduo ou grupo específico). Para esta última estrutura de propriedade e controle atribuíram a classificação: “a) familiar ou individual; b) o Estado; c) uma instituição financeira com controle disperso, como um banco ou uma companhia de seguros; d) uma corporação com controle disperso; e) diversos, tais como uma cooperativa, ou um grupo com nenhum único investidor controlador" (La Porta, Lopez-de-Silanes e Shleifer, 1998, p. 10)

Esta característica de concentração ou dispersão na estrutura de propriedade e controle pode variar de acordo com o ambiente de atuação da empresa, pois está associada a vários fatores, como regime político, sistema legal, estrutura do mercado de capitais, experiência histórica de industrialização, condições geográficas e cultura (Demsetz, \& Lehn, 1985, Siffer Filho, 1998). Neste aspecto se configura o entendimento de concentração de propriedade e estrutura das empresas brasileiras. Segundo Sarlo Neto, Lopes e Dalmácio (2009, p. 5), "devido à possibilidade de montar estruturas piramidais de controle e de emissão de ações preferenciais, os acionistas controladores tendem a deter, em sua participação acionária, maior quantidade de direitos de votos do que direitos de fluxo de caixa".

Torres, Bruni, Rivera-Castro e Martinez (2010, p. 14), em seus estudos sobre a estrutura de propriedade e controle de empresas brasileiras, apontam que "dada a alta concentração da estrutura de propriedade e controle no Brasil, os conflitos de interesse nas firmas brasileiras são primeiramente associados a acionistas controladores e acionistas minoritários". Conforme Dami, Rogers e Ribeiro (2007, p. 22), a existência dos conflitos, custos de agência e direitos assimétricos 
Relação entre as práticas do board interlocking e características de empresas de estrutura de propriedade familiar com ações mais negociadas na BM\&FBOVESPA

estabelece a necessidade da adoção de mecanismos de controle para que o processo de governança harmonize os interesses das partes envolvidas com as operações da empresa.

Nesse contexto a estrutura de propriedade é apresentada como um dos principais mecanismos de governança corporativa (Leal, Silva, \& Valadares, 2002). Outro mecanismo importante refere-se ao conselho de administração, que é apontado como elo entre a propriedade e gestão das empresas, ressaltando que "a independência entre ambos pode garantir eficiência na administração em que o conselho de administração manter-se-ia essencialmente independente dos diretores executivos" (Mendes-da-Silva, \& Grzybovski, 2006, p. 49). Esta independência entre propriedade e conselho de administração é um dos temas centrais quando é abordada a temática da estrutura de propriedade e controle concentrada, característico de estudos que abrangem as empresas familiares.

\subsection{Empresas Familiares e Conselho de Administração}

As empresas familiares em âmbito universal demonstram relevância no contexto econômicosocial, representando a modalidade mais simples e antiga das organizações. Esta afirmação, sustentada por autores, configura-se também no ambiente corporativo brasileiro. A definição de empresa familiar compreende "negócios em que a propriedade e a gestão são de uma ou mais famílias, que sofrem a influência dela(s) na tomada de decisão e na qual existe a intenção de transferir a empresa (propriedade e gestão) para a próxima geração" (Mendes-da-Silva, \& Grzybovski, 2006, p. 47).

Boff, Beuren e Hein (2009, p. 251) apontam a empresa familiar como provinda da origem e continuidade da organização com base no projeto idealizado por um fundador, empreendedor ou grupo de pessoas vinculadas entre si que detém a propriedade e controle do negócio. Os autores acrescentam que esta característica familiar persiste mesmo quando a gestão está sob a responsabilidade de administradores contratados.

Em empresas familiares observa-se alta concentração de propriedade e controle, o que condiz com a estrutura de propriedade acionária brasileira. Segundo Dami, Rogers, Ribeiro (2007, p. 26), esta contribui sobremaneira para o principal conflito de agência no Brasil entre acionistas minoritários e acionistas majoritários, que no contexto familiar caracterizam-se em acionistas familiares e acionistas externos. De acordo com Anderson e Reeb (2004), este conflito é minimizado por meio da atuação de conselheiros independentes.

Beuren e Muller (2010, p. 48) mencionam que as empresas familiares apresentam peculiaridades em relação às demais sociedades no sentido de apresentarem associados à sua estrutura, a cultura e o sistema familiar. O conflito de agência nestas organizações recebe reflexos desta particularidade inerente às empresas familiares, fazendo-se necessários mecanismos que auxiliam na minimização destes conflitos, como o Conselho de Família.

Conforme orientação do Instituto Brasileiro de Governança Corporativa (IBGC, 2011), empresas familiares devem implementar um Conselho de Família, que difere essencialmente do Conselho de Administração, pois tem como finalidade a discussão de assuntos familiares e o alinhamento das expectativas de seus integrantes em relação a organização, além da aplicação das demais boas práticas de governança corporativa, a fim de minimizar o conflito de agência.

O Conselho de Administração, tido como principal componente do sistema de governança, intermedeia a relação entre diversos interessados na organização, ou seja, configura-se como elo principal entre a gestão da organização e a propriedade (IBGC, 2011; Mendes-da-Silva, \& Grzybovski, 2006). Este instrumento de governança corporativa oferece ainda outra vantagem às empresas familiares, a "oportunidade de melhorar a qualidade da gestão, mediante a possibilidade de contribuição de conselheiros externos qualificados" (Gomes, Souza Neto, \& Martins, 2006, p. 1).

Alguns pontos fortes relacionados ao conselho de administração são apontados no intuito de direcionar o entendimento do tema proposto no estudo. Em seu Código de Melhores Práticas de Governança Corporativa, o IBGC (2011, p. 34) elenca como uma das qualidades do conselheiro a disponibilidade de tempo, reforçando que a "participação do conselheiro vai além da presença nas reuniões do Conselho e da leitura da documentação previa".

Quanto à participação em outros conselhos e comitês, apresentam-se a seguir as recomendações pautadas nas seguintes diretrizes do IBGC (2011, p. 34):

a) O presidente do Conselho de Administração poderá participar como conselheiro de, no máximo, dois outros conselhos; 
b) Conselheiros externos e/ou independentes que não tenham outra atividade poderão participar de, no máximo, cinco conselhos;

c) Executivos seniores poderão participar como conselheiros de apenas uma organização, salvo se tratar de empresa coligada ou do mesmo grupo;

d) Conselheiros internos e/ou diretor-presidente poderão participar de, no máximo, um outro Conselho, salvo se tratar de empresa coligada ou do mesmo grupo;

e) Presidentes executivos e presidente do conselho não devem exercer cargo de presidência do Conselho de outra organização (com exceção para entidades do terceiro setor), salvo se tratar-se de empresa coligada ou do mesmo grupo.

Mendes-da-Silva e Grzybovski (2006, p. 49) ressaltam ainda que a independência entre Conselho da Administração e Diretoria pode garantir maior eficiência das atividades administrativas. Portanto, quando os conselheiros não participam da diretoria da organização, sinalizam um grau de independência em suas ações.

Em decorrência da importância atribuída a este conselho nas organizações, pesquisas vêm sendo realizadas no ambiente acadêmico com o intuito de examinar: as características deste órgão no ambiente brasileiro, sua influência no desempenho das organizações, poder de limitação desse conselho em relação ao gerenciamento de resultados, configuração de laços entre os membros de diferentes empresas (Mendes-da-Silva, \& Grzybovski, 2006; Marra, Mazzola, \& Prencipe, 2011; Jaggi, Leung, \& Gul, 2009). Há diversos estudos que ampliam o entendimento do assunto e remetem a novas pesquisas.

\subsection{Board Interlocking e Relacionamentos Intercorporativos}

Heng e Gygax (2009) definem a prática do Board Interlocking como um relacionamento criado entre dois conselhos de empresas diferentes quando compartilham pelo menos um membro em comum. De acordo com Mizruchi (1996), o Board Interlocking pode originar-se da interligação existente entre conselheiros que operam dentro ou fora das companhias, podem ser fundadores, investidores, ou representantes de grupos de interesses.

O interlocking, segundo Szalacha (2010), é o resultado de escolhas individuais feitas pelos membros dos conselhos, que buscam atender aos interesses das companhias, enquanto promovem seus próprios interesses. A autora considera que os membros em comum possuem compromissos em comum em empresas diferentes, por participarem simultaneamente dos conselhos de diferentes empresas.

Mendes-da-Silva (2010, p. 5) pondera que o Board Interlocking se refere "ao fato de uma ou mais pessoas participarem, simultaneamente, do conselho de administração de empresas diferentes, possibilitando a formação de redes corporativas e pessoais, nas quais são criados fluxos de recursos essenciais à empresa". Santos e Silveira $(2007$, p. 126) ressaltam que o Conselho de Administração "é considerado um dos principais mecanismos internos de governança corporativa, em função de suas atribuições de monitoramento dos gestores, ratificação das decisões relevantes e fixação das diretrizes estratégicas da companhia".

A prática do Board Interlocking pode decorrer de motivações de cunho organizacional, pessoal e social (Mendes-da-Silva, 2010). Uma subdivisão da prática do interlockig é apresentada por Santos e Silveira (2007, p. 131) como segue: simple Board Interlocking; reciprocal Board Interlocking. O primeiro "ocorre quando o profissional da empresa $i$ ocupa cargo de conselheiro na empresa $j$, mas nenhum profissional desta atua na primeira empresa". O segundo é menos frequente e ocorre "quando o profissional da empresa i ocupa cargo de conselheiro na empresa $j$ e, reciprocamente, um profissional da $j$ também trabalha na empresa i" (Santos, \& Silveira, 2007, p. 131).

Heng e Gygax (2009) constataram que os diretores podem encontrar-se nos conselhos de múltiplas empresas, isso se deve ao fato de existir duas participações simultâneas, ou seja, quando as empresas são interligadas por possuírem pelo menos um membro do conselho em comum. Assim, consideram que pode existir também uma rede formada por um conjunto de empresas, que estariam interligadas por meio de seus membros em comum. Os autores consideram essa rede como uma configuração interempresarial, que poderia ser denominada de interlocking, ou ainda interfirma, que tem influência nas decisões empresariais.

Estudos que investigaram a prática do Board Interlocking já estão em discussão há algum tempo em outros países, conforme demonstram de Dooley (1969), Allen (1974), Mizruchi (1996), Fich e White (2005), Fich e Shivdasani (2006). No Brasil foi identificada a pesquisa realizada por 
Relação entre as práticas do board interlocking e características de empresas de estrutura de propriedade familiar com ações mais negociadas na BM\&FBOVESPA

Santos e Silveira (2007), considerada a pioneira. Neste estudo os autores investigaram a participação simultânea de conselheiros em diferentes conselhos de administração de 320 empresas brasileiras nos anos de 2003 e 2005. Também investigaram se a ocorrência dessa prática traz consequências para o valor de desempenho das empresas.

Os resultados mostraram que o Board Interlocking é uma prática frequente no Brasil e fatores como conselho maior, controle acionário disperso e maior porte da empresa estão relacionados com a prática do Board Interlocking nas companhias. Além disso, observaram que empresas com altos níveis de interlocking têm seu valor corporativo prejudicado, principalmente em casos que metade ou mais dos conselheiros participam de três ou mais conselhos, ou naquelas em que o diretorexecutivo atua em outros conselhos.

No entanto, Szalacha (2010) destaca que pode haver benefícios na interligação de membros das empresas. Estes podem ocorrer no sentido dos conselheiros comunicarem informações a respeito de preços, propagandas, pesquisa e desenvolvimento, úteis a ambas as companhias. Já num segundo momento, a autora infere que benefícios internos em relação à coordenação e perícia nos serviços da empresa podem ser alcançados por esses membros externos, no que diz respeito a alternativas no momento de tomar decisões e em relação ao capital social. Destaca ainda outro benefício, a reputação corporativa.

Outros estudos buscaram verificar a pratica do Board Interlocking por meio da aplicação de redes sociais, relacionando-as com outros fatores como estrutura de propriedade, desempenho e governança corporativa. Nesse sentido destacam-se os estudos de Mendes-da-Silva, Rossoni, Martin e Martelanc (2008), Mendes-da-Silva e Vidal (2010), Drago, Millo, Ricciuti e Santella (2011).

Mendes-da-Silva e Vidal (2010) buscaram analisar a evolução da configuração da rede de relações entre os membros dos conselhos das empresas de capital aberto listadas no Brasil entre 1997 e 2007, tendo por base a teoria dos gráficos de suposições e a abordagem dos mundos pequenos. Os autores concluíram que o interlocking reflete a estratificação no ambiente corporativo no Brasil e está associado com o desempenho do conselho em sua prática gerencial. Além disso, observaram um aumento significativo na rede de relacionamentos entre membros, com diminuição da densidade nos laços estabelecidos para a participação comum em uma ou mais placas.

\section{Procedimentos Metodológicos}

No que concerne ao delineamento metodológico, esta pesquisa classifica-se quanto aos objetivos como descritiva, conforme preceituado por Vergara (1998), uma vez que expõe características do fenômeno focalizado na pesquisa. Quanto aos meios, trata-se de pesquisa documental de acordo com o preconizado por Gil (2010). A abordagem do problema é de natureza quantitativa, que segundo Richardson (1999) emprega técnicas estatísticas no tratamento dos dados.

\subsection{Hipóteses}

A análise da governança corporativa, incluindo-se a transparência da administração, tem se tornado um fator chave para conhecer as grandes empresas, além de "ser apontada como um indicador de confiança dos investidores nas decisões tomadas pela administração das empresas listadas em bolsas de valores" (Mendes-da-Silva, \& Grzybovski, 2006, p. 46).

Incluem-se nesse contexto as companhias familiares listadas na BM\&FBovespa, que também devem estar atentas a esses aspectos, mesmo possuindo características conservadoras quanto a forma de gestão e coordenação de suas atividades. Isso deve ser considerado apesar de sua estrutura de propriedade ser de controle concentrado, definido por um único acionista controlador ou por controle compartilhado por membros da mesma família (La Porta, Lopez-de-Silanes, \& Shleifer, 1999).

Estudos anteriores realizados por Dani, Beck, Almeida-Santos e Lavarda (2013) em empresas familiares e por Beuren, Dani, Dal Vesco e Krespi (2013) em empresas não familiares, apontam que a prática do Board Interlocking pode ser considerada como um mecanismo de governança corporativa. Segundo Beuren et al. (2013, p. 314), "essa prática associa-se a necessidade constante de fluxos de informações financeiras, sustentáveis e gerenciais por parte dos membros de seus conselhos, visando a melhoria do controle interno e atendimento de interesses dos diversos usuários". 
Por outro lado, algumas características das empresas familiares as diferenciam de forma negativa das não familiares, que podem impedir que membros dessas empresas alterem sua postura e realizem uma migração para outras empresas, ou mesmo a prática do Board Interlocking. Dentre as características negativas destaca-se a gestão centralizada, autoritária e intuitiva (Welsh, \& Raven, 2006) e o jogo de poder, que às vezes faz valer mais a habilidade política ou o fato de ser da família do que a capacidade administrativa (Lodi, 1998).

Ressalta-se que não há um consenso na literatura de que as empresas familiares brasileiras sejam menos propensas a ocorrência da prática do Board Interlocking do que as não familiares, pelo fato de ser um assunto ainda pouco difundido na literatura nacional.

Nesta pesquisa, parte-se da premissa de que as companhias brasileiras que possuem estrutura de propriedade com controle familiar são menos propensas a possuírem membros em comum, com laços de parentesco ocupando cargos concomitantemente em outras empresas, devido ao fato de possuírem, em sua grande maioria, uma estrutura de propriedade com controle e capital concentrado e com um modelo de gestão conservador. Mesmo que existam fatores externos de mercado que influenciam nas decisões empresariais, no caso das empresas familiares a natureza controladora e centralizadora se sobrepõe a tendência do Board Interlocking comum em empresas não familiares.

Para tanto, busca-se averiguar essa relação pretendida, pelo fato de as empresas familiares brasileiras possuírem necessidades e peculiaridades que as diferenciam das demais, e tornam sua estrutura de propriedade e governança corporativa únicas. A partir desse ambiente, formularam-se as seguintes hipóteses da pesquisa:

$H_{0}$ : Companhias que possuem estrutura de propriedade com controle familiar não são propensas a ocorrência do Board Interlocking.

$\mathrm{H}_{1}$ : Companhias que possuem estrutura de propriedade com controle familiar são propensas a ocorrência do Board Interlocking.

\subsection{Variáveis Utilizadas}

Com vistas ao atendimento do objetivo proposto no estudo, definiu-se um conjunto de 15 variáveis que foram segmentadas em dois grupos. O primeiro grupo refere-se as variáveis de caracterização das empresas. O segundo grupo refere-se as variáveis que caracterizam a prática do Board Interlocking em empresas com estrutura de propriedade familiar. Nesse sentido destaca-se individualmente cada variável utilizada e sua descrição:

Grupo 1 - Variáveis relacionadas às características das empresas com estrutura de propriedade familiar (determinantes):

M. ADM - Número de membros no conselho de administração;

ANO - Variável binária indicando o período correspondente às informações coletadas, sendo os anos de 2010 e 2011;

C. F. - Número de membros do conselho fiscal;

M. COMITÉ AUDITORIA - Número de membros do comitê de auditoria;

M. DIRET. - Número de membros da diretoria;

M. INDEPENDENTES - Número de membros independentes;

M. OUTROS COMITÉS - Número de membros componentes de outros comitês;

OUTROS CONSELHEIROS - Número de membros integrantes de outros comitês;

TAM - Tamanho da empresa, medida pelo total do ativo.

Grupo 2 - Variáveis do Board Interlocking de empresas com estrutura de propriedade familiar:

BOARD INTERLOCKING - Variável binária indicando se a empresa possui ao menos um conselheiro de outra companhia;

CEOCHAIR - Número de Board Interlocking ocorridos com membros de diferentes setores dentro da própria companhia;

R. COM 1 GRAU DE PARENTESCO - Número de relações de parentesco de 1 o grau entre os membros que compõem o conselho de cada empresa;

R. COM 2 GRAU DE PARENTESCO - Número de relações de parentesco de 20 grau entre os membros que compõem o conselho de cada empresa. 
Relação entre as práticas do board interlocking e características de empresas de estrutura de propriedade familiar com ações mais negociadas na BM\&FBOVESPA

Dos estudos relacionados à pratica do Board Interlocking, acima apresentados, como marco teórico destaca-se o estudo realizado por Santos e Silveira (2007), que avaliaram a presença da prática do Board Interlocking nas empresas brasileiras. Além disso, identificaram as características financeiras e de controle e gestão das companhias que estavam associadas à existência em maior ou menor grau dessa prática. Por último, verificaram a influência do fenômeno sobre o valor e desempenho das empresas. Assim, neste estudo utilizaram-se variáveis semelhantes aquelas selecionadas por Santos e Silveira (2007).

Dentre as variáveis utilizadas no estudo de Santos e Silveira (2007), destaca-se para esta pesquisa o INTERLOCK como variável dependente (indicando se a empresa possui ao menos um conselheiro que atua também no conselho de outra companhia). Tendo por base a definição apresentada por Mizruchi (1996), consideraram-se nesta pesquisa os membros participantes nos seguintes cargos concomitantes: diretoria (D.); conselho de administração (C.A.); conselho fiscal (C.F.); outros conselheiros (O.C.).

Como variáveis explicativas, utilizaram-se: SETOR (indicando o setor ao qual a companhia pertence); ANO (indicando o ano analisado); TAMCONS (número de membros no conselho de administração); INDEP (grau de independência, calculado como porcentagem de conselheiros externos menos a porcentagem de conselheiros internos); CEOCHAIR (indicando se a empresa possui o mesmo profissional nos cargos de diretor executivo e presidente do conselho de administração); CONTROL (porcentagem de ações ordinárias em posse do bloco controlador); outras variáveis relacionadas ao desempenho das companhias.

No presente estudo optou-se por dividir as variáveis em dois grupos principais, sendo o primeiro grupo formado pelas variáveis relacionadas às características das empresas com estrutura de propriedade familiar (variáveis grupo 2); e num segundo grupo aquelas relacionadas ao Board Interlocking (variáveis grupo 1).Destaca-se que todas as empresas analisadas estão listadas nos níveis de governança. Isso pressupõe que as empresas analisadas possuem membros nos conselhos com alta reputação no mercado de gestão corporativa e, por essa razão, são convidados a desempenhar cargos em outras companhias, podendo ter uma considerável participação no conselho das companhias (Santos, \& Silveira, 2007).

\subsection{Universo e Amostra}

O universo da pesquisa compõe-se das 100 companhias com ações mais negociadas na BM\&FBovespa, classificadas pela Revista Capital Aberto em edição especial, denominada Anuário de Governança Corporativa das companhias abertas do ano de 2010. Presume-se que estas companhias, devido ao seu porte, apresentam ligações entre conselheiros de empresas. Investigar as implicações das ligações existentes entre conselheiros é uma extensão natural da literatura de governança corporativa (Stuart, \& Yim, 2010).

Neste universo de 100 companhias foram investigadas 23 empresas classificadas pelo anuário como familiares. A seleção da amostra foi realizada intencionalmente em função do tipo de propriedade e controle das empresas. Essas empresas possuem uma tendência de apresentar uma estrutura de propriedade mais concentrada. No estudo focalizou-se a relação do Board Interlocking e características das empresas familiares, portanto, na delimitação da amostra consideraram-se empresas com estrutura de propriedade e controle familiar.

\subsection{Coleta dos Dados}

Os dados referentes as 23 empresas da amostra foram coletados nos relatórios financeiros de 2010 e 2011, disponíveis no sítio da BM\&FBovespa. Nos Formulários de Referência coletaram-se os dados relativos a composição dos conselhos das empresas e do grau de parentesco dos membros diretivos das empresas. Coletaram-se também dados no Anuário de Governança Corporativa das companhias abertas do ano de 2010.

\subsection{Procedimentos de Análise dos Dados}

Por meio de estatística descritiva busca-se identificar os aspectos das empresas componentes da amostra no que tange ao setor de atuação, a caracterização da prática do Board Interlocking, o mapeamento das relações entre as empresas e seus membros, e as relações familiares nos conselhos das empresas analisadas. Com a análise da correlação busca-se verificar se existe relação 
entre a prática do Board Interlocking e as características de empresas de estrutura de propriedade e controle familiar. Destaca-se que o procedimento estatístico foi realizado com o auxílio do software SPSS.

\section{Descrição e Análise dos Resultados}

\subsection{Estatística Descritiva}

Na Tabela 1 evidenciam-se os diferentes setores de atuação das empresas componentes da amostra, conforme classificação da BM\&FBovespa em 2011.

Observa-se na Tabela 1, que os setores econômicos de construção e transporte e de materiais básicos foram aqueles que apresentaram maior participação relativa na amostra de empresas com controle do tipo familiar analisadas. Destacaram-se os segmentos de construção civil e de papel e celulose, ambos com 13,04\% de frequência, ou seja, são os setores mais presentes na amostra. Em contrapartida, observa-se que os demais setores apresentaram uma frequência relativa menor, com 4,35\%, totalizando 18 empresas. Observa-se que a amostra não está concentrada em setores específicos, e que de forma geral apresenta empresas nos mais diversos segmentos do mercado.

Para o levantamento da prática do Board Interlocking nas empresas analisadas, buscou-se identificar primeiramente a caracterização destes membros e conselhos, no que se refere ao cargo que ocupam. A Lei $n^{\circ}$. 10.303/01, que altera dispositivos da Lei $n^{\circ} .6 .385 / 76$ e da Lei $n^{\circ} .6 .404 / 76$, aponta em seu art. 147, parágrafo terceiro, que o conselheiro da empresa preferencialmente não deve ocupar cargos em empresas concorrentes, principalmente se estes cargos relacionarem-se ao conselho consultivo, de administração e fiscal.

Tabela 1

Setor de atuação das empresas com controle familiar componentes da amostra

\begin{tabular}{|c|c|c|c|c|}
\hline Setor & Segmento & $\begin{array}{c}\text { Frequênci } \\
\text { a } \\
\text { Absoluta }\end{array}$ & $\begin{array}{c}\text { Frequência } \\
\text { Absoluta }\end{array}$ & $\begin{array}{c}\text { Frequência } \\
\text { Relativa }\end{array}$ \\
\hline Utilidade pública & Energia Elétrica & 1 & $4,35 \%$ & 1 \\
\hline \multirow[t]{3}{*}{ Financeiro e Outros } & Bancos & 1 & $4,35 \%$ & 2 \\
\hline & $\begin{array}{l}\text { Holding de } \\
\text { Participações }\end{array}$ & 1 & $4,35 \%$ & 3 \\
\hline & Seguros & 1 & $4,35 \%$ & 4 \\
\hline \multirow[t]{2}{*}{ Consumo não Cíclico } & Alimentos & 2 & $8,70 \%$ & 6 \\
\hline & Saúde & 1 & $4,35 \%$ & 7 \\
\hline \multirow[t]{4}{*}{ Bens Industriais } & Aviação & 1 & $4,35 \%$ & 8 \\
\hline & Comércio & 1 & $4,35 \%$ & 9 \\
\hline & Material e Transporte & 1 & $4,35 \%$ & 10 \\
\hline & $\begin{array}{l}\text { Maquinas e } \\
\text { equipamentos }\end{array}$ & 2 & $8,70 \%$ & 12 \\
\hline Construção e Transporte & Construção Civil & 3 & $13,04 \%$ & 15 \\
\hline \multirow[t]{6}{*}{ Materiais Básicos } & Metalurgia e Siderurgia & 2 & $8,70 \%$ & 17 \\
\hline & Papel e Celulose & 3 & $13,04 \%$ & 20 \\
\hline & Materiais Diversos & 1 & $4,35 \%$ & 21 \\
\hline & Mineração & 1 & $4,35 \%$ & 22 \\
\hline & $\begin{array}{l}\text { Petroquímicos e } \\
\text { Borracha }\end{array}$ & 1 & $4,35 \%$ & 23 \\
\hline & Total & 23 & $100 \%$ & - \\
\hline
\end{tabular}

Nota. Fonte: Dados da pesquisa.

Visto que os estudos de Fich e White (2005) e Santos e Silveira (2007) apontam que a participação em conselhos múltiplos pode se refletir em falta de tempo para execução das tarefas dos conselheiros, e poder de influência em decisões estratégicas, considerou-se para a prática do Board Interlocking os membros participantes nos seguintes cargos concomitantes: diretoria (D.); conselho de administração (C.A.); conselho fiscal (C.F.); outros conselheiros (O.C.). Na Figura 1 demonstra-se a participação de membros em conselhos múltiplos identificada na pesquisa documental realizada.

Verifica-se a prática do Board Interlocking em aproximadamente 57\% das 23 empresas da 
amostra, o que indica ser uma prática comum entre as empresas analisadas. Os membros em sua maioria atuam concomitantemente no conselho de administração nas empresas. No entanto, mesmo que de forma menos expressiva, esta prática ocorre também com membros dos cargos de diretoria, outros conselheiros e conselho fiscal.

Este levantamento compreende os exercícios de 2010 e 2011, não sendo apontadas muitas alterações entre as relações e cargos, o que se justifica em função da renovação dos conselhos variar de empresa para empresa, bem como pode ser motivada por uma decisão do conselheiro. Por exemplo, o conselheiro da TAM em 2010, Sr. André Santos Esteves, apresentou em 2011 participação tanto no conselho de administração da empresa TAM como no Banco Panamericano. Neste sentido, a Figura 2, busca mapear a relação verificada entre as empresas no terceiro trimestre de 2011, indicando os membros que configuram estas relações.

\begin{tabular}{|c|c|c|c|c|}
\hline \multirow{2}{*}{ Membro } & \multicolumn{2}{|l|}{ Ano 2011} & \multicolumn{2}{|l|}{ Ano 2010} \\
\hline & Empresa & Cargo & Empresa & Cargo \\
\hline Affonso Celso Pastore & $\begin{array}{l}\text { EVEN } \\
\text { GERDAU }\end{array}$ & $\begin{array}{l}\text { C.A. } \\
\text { C.A. }\end{array}$ & $\begin{array}{l}\text { EVEN } \\
\text { TAM }\end{array}$ & $\begin{array}{l}\text { C.A. } \\
\text { C.A. }\end{array}$ \\
\hline André Santos Esteves & $\begin{array}{l}\text { PANAMERICANO } \\
\text { TAM }\end{array}$ & $\begin{array}{l}\text { C.A. } \\
\text { C.A. }\end{array}$ & - & - \\
\hline $\begin{array}{l}\text { Carlos Roberto de } \\
\text { Albuquerque Sá }\end{array}$ & $\begin{array}{l}\text { MINERVA } \\
\text { MARFRIG }\end{array}$ & $\begin{array}{l}\text { D. } \\
\text { C.F. }\end{array}$ & - & - \\
\hline $\begin{array}{l}\text { Eduardo Grande } \\
\text { Bittencourt }\end{array}$ & $\begin{array}{l}\text { MARCOPOLO } \\
\text { WEG }\end{array}$ & $\begin{array}{l}\text { C.F. } \\
\text { C.F. }\end{array}$ & $\begin{array}{l}\text { MARCOPOLO } \\
\text { WEG } \\
\text { GERDAU }\end{array}$ & $\begin{array}{l}\text { C.F. } \\
\text { C.F. } \\
\text { C.F. }\end{array}$ \\
\hline Egon Handel & $\begin{array}{l}\text { MPX } \\
\text { MARCOPOLO }\end{array}$ & $\begin{array}{l}\text { C.A. } \\
\text { C.F. }\end{array}$ & $\begin{array}{l}\text { GERDAU } \\
\text { MARCOPOLO }\end{array}$ & $\begin{array}{l}\text { C.F. } \\
\text { C.F. }\end{array}$ \\
\hline Eike Fuhrken Batista & $\begin{array}{l}\text { MMX } \\
\text { MPX }\end{array}$ & $\begin{array}{l}\text { C.A. } \\
\text { C.A. }\end{array}$ & $\begin{array}{l}\text { MMX } \\
\text { MPX }\end{array}$ & $\begin{array}{l}\text { C.A. } \\
\text { C.A. }\end{array}$ \\
\hline Eliezer Batista da Silva & $\begin{array}{l}\text { MMX } \\
\text { MPX }\end{array}$ & $\begin{array}{l}\text { O.C. } \\
\text { C.A. }\end{array}$ & $\begin{array}{l}\text { MMX } \\
\text { MPX }\end{array}$ & $\begin{array}{l}\text { O.C. } \\
\text { C.A. }\end{array}$ \\
\hline $\begin{array}{l}\text { Luiz do Amaral de } \\
\text { França Pereira }\end{array}$ & $\begin{array}{l}\text { MMX } \\
\text { MPX }\end{array}$ & $\begin{array}{l}\text { C.A. } \\
\text { C.A. }\end{array}$ & $\begin{array}{l}\text { MMX } \\
\text { MPX }\end{array}$ & $\begin{array}{l}\text { C.A. } \\
\text { C.A. }\end{array}$ \\
\hline Marco Antônio Bologna & $\begin{array}{l}\text { SUZANO } \\
\text { TAM }\end{array}$ & $\begin{array}{l}\text { C.A. } \\
\text { C.A. e } \\
\text { D. }\end{array}$ & $\begin{array}{l}\text { SUZANO } \\
\text { TAM }\end{array}$ & $\begin{array}{l}\text { C.A. } \\
\text { C.A. }\end{array}$ \\
\hline Nildemar Secches & $\begin{array}{l}\text { SUZANO } \\
\text { WEG }\end{array}$ & $\begin{array}{l}\text { C.A. } \\
\text { C.A. }\end{array}$ & $\begin{array}{l}\text { SUZANO } \\
\text { WEG }\end{array}$ & $\begin{array}{l}\text { C.A. } \\
\text { C.A. }\end{array}$ \\
\hline $\begin{array}{l}\text { Oscar de Paula } \\
\text { Bernardes Neto }\end{array}$ & $\begin{array}{l}\text { GERDAU } \\
\text { LOCALIZA } \\
\text { SUZANO }\end{array}$ & $\begin{array}{l}\text { C.A. } \\
\text { C.A. } \\
\text { C.A. }\end{array}$ & $\begin{array}{l}\text { GERDAU } \\
\text { LOCALIZA } \\
\text { SUZANO }\end{array}$ & $\begin{array}{l}\text { C.A. } \\
\text { C.A. } \\
\text { C.A. }\end{array}$ \\
\hline Samir Zraick & $\begin{array}{l}\text { MMX } \\
\text { MPX }\end{array}$ & $\begin{array}{l}\text { C.A. } \\
\text { C.A. }\end{array}$ & $\begin{array}{l}\text { MMX } \\
\text { MPX }\end{array}$ & $\begin{array}{l}\text { C.A. } \\
\text { C.A. }\end{array}$ \\
\hline Sérgio Bernstein & $\begin{array}{l}\text { EVEN } \\
\text { |GUATEMI }\end{array}$ & $\begin{array}{l}\text { C.F. } \\
\text { C.A. }\end{array}$ & $\begin{array}{l}\text { EVEN } \\
\text { |GUATEM| }\end{array}$ & $\begin{array}{l}\text { C.F. } \\
\text { C.F. }\end{array}$ \\
\hline
\end{tabular}

Figura 1 - Relação de membros participantes simultaneamente em duas ou mais empresas Nota. Fonte: Dados da pesquisa.

A Figura 2 mostra que em sua maioria as relações entre os conselhos são estabelecidas por um membro em comum, e que há predominância do membro atuar em apenas duas empresas. Ocorrem, no entanto, particularidades nos quesitos apresentados em relação ao membro Sr. Oscar de Paula Bernardes Neto, que atua no conselho de administração das empresas Localiza, Gerdau e Suzano. Verifica-se também um caso isolado na ligação entre as empresas MMX e MPX, em que há participação nestas de quatro membros em comum. 


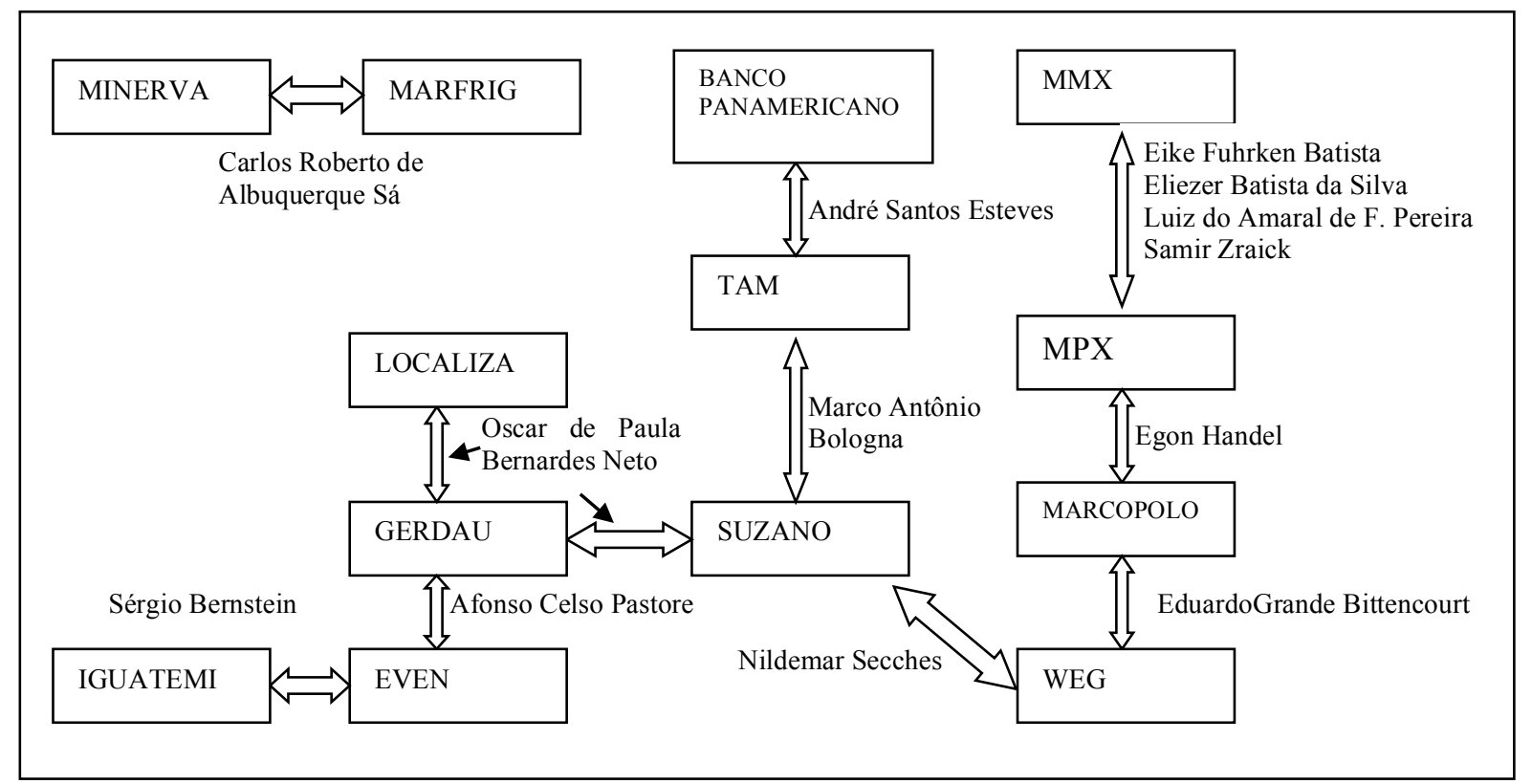

Figura 2 - Mapeamento das empresas interligadas em 2011

Nota. Fonte: Dados da pesquisa.

Pontua-se ainda a ocorrência de grau de parentesco entre dois conselheiros: Sr. Eike Fuhrken Batista e Sr. Eliezer Batista da Silva. Esse achado leva à análise de ocorrência de relação de parentesco entre os membros do conselho e a direção das empresas analisadas, pontuando ainda, que se trata de empresas familiares, ou seja, as características familiares transpassam a estrutura de propriedade (Boff, Beuren, \& Hein, 2009). Neste sentido apresenta-se na Tabela 2 o número de relações de parentesco verificadas entre os membros (diretores e conselheiros) nas empresas analisadas.

Tabela 2

Número de relações de parentesco entre os membros do conselho e diretores

\begin{tabular}{|c|c|c|c|c|}
\hline \multirow[b]{2}{*}{ Empresa } & \multicolumn{2}{|c|}{2011} & \multicolumn{2}{|c|}{2010} \\
\hline & $\begin{array}{c}\mathrm{N}^{\circ} \cdot \mathrm{de} \\
\text { Relações de } \\
1^{\circ} \mathrm{Grau}\end{array}$ & $\begin{array}{c}\mathrm{N}^{\circ} \cdot \mathrm{de} \\
\text { Relações de } \\
2^{\circ} \mathrm{Grau}\end{array}$ & $\begin{array}{c}\mathrm{N}^{\circ} \cdot \mathrm{de} \\
\text { Relações de } \\
1^{\circ} \mathrm{Grau}\end{array}$ & $\begin{array}{c}\mathrm{N}^{\circ} \text {. de } \\
\text { Relações de } \\
2^{\circ} \mathrm{Grau}\end{array}$ \\
\hline AMIL & 0 & 0 & 0 & 0 \\
\hline BRASKEM & 21 & 12 & 21 & 12 \\
\hline SID NACIONAL & 5 & 0 & 0 & 0 \\
\hline EVEN & 1 & 0 & 1 & 0 \\
\hline GERDAU & 14 & 0 & 14 & 0 \\
\hline GOL & 16 & 0 & 16 & 0 \\
\hline |GUATEMI & 7 & 0 & 7 & 0 \\
\hline ITAUSA & 7 & 0 & 7 & 0 \\
\hline JHSF & 3 & 0 & 3 & 0 \\
\hline KLABIN & 15 & 0 & 15 & 0 \\
\hline LOCALIZA & 2 & 0 & 2 & 0 \\
\hline MARCOPOLO & 1 & 0 & 1 & 0 \\
\hline MARFRIG & 1 & 1 & 1 & 1 \\
\hline MINERVA & 43 & 0 & 3 & 0 \\
\hline$M M X$ & 2 & 0 & 2 & 0 \\
\hline MPX & 1 & 0 & 1 & 0 \\
\hline MRV & 3 & 0 & 3 & 0 \\
\hline PANAMERICANO & 0 & 0 & 0 & 0 \\
\hline PORTO SEGURO & 0 & 0 & 0 & 0 \\
\hline RANDON & 7 & 0 & 7 & 0 \\
\hline SUZANO & 14 & 0 & 4 & 0 \\
\hline TAM & 6 & 0 & 6 & 6 \\
\hline WEG & 1 & 0 & 1 & 0 \\
\hline
\end{tabular}

Nota. Fonte: Dados da pesquisa. 
Observa-se na Tabela 2, que a grande maioria das empresas da amostra apresenta relação de parentesco entre os membros que compõem a direção e conselho da empresa, bem como a predominância de relações de parentescos de $1^{\circ}$ grau. Estas informações configuram-se como características desta amostra e fazem parte na análise estatística utilizada.

\subsection{Correlação das Variáveis}

Antes de se proceder à análise de correlação das variáveis, faz-se necessário verificar se as mesmas seguem uma distribuição normal, a fim de obter uma representação mais fidedigna dos coeficientes de correlação. Nesta perspectiva, aplicou-se o teste não paramétrico de KolmogorovSmirnov, para testar as seguintes hipóteses:

$\mathrm{H}_{0}$ : Os dados seguem uma distribuição normal.

$\mathrm{H}_{1}$ : Os dados não seguem uma distribuição normal.

Tabela 3

Teste não paramétrico de Kolmogorov-Smirnov Total N

Diferenças Mais Extremas

Absoluta 23

Estatistica do Teste Positiva

0,351

Negativa

Sig.

Nota. Outputs do SPSS 20.0. Fonte: Dados da pesquisa.

0,007

Observa-se na Tabela 3 que o resultado do $p$-value do teste em destaque é menor que $5 \%$ ( $p<$ $0,05)$, nível de significância assumido para o teste da hipótese nula, $H_{0}$, isto é, $p=0,007<p=0,05$, levando à rejeição da mesma, ou seja, os dados não seguem uma distribuição normal, sendo, portanto, recomendável a aplicação do teste de correlação de Spearman, o qual despreza o pressuposto de normalidade dos dados, e devido à quantidade dos casos em observação $(\mathrm{N}=23)$.

Na Tabela 4 apresenta-se a correlação entre as variáveis que representam o Board Interlocking e os determinantes da estrutura de propriedade.

Tabela 4

Correlação de Spearman das variáveis

\begin{tabular}{|c|c|c|c|c|c|c|c|c|c|c|c|}
\hline & \multicolumn{7}{|c|}{ Estrutura Familiar } & \multicolumn{4}{|c|}{ Board Interlocking } \\
\hline & $\times 01$ & $\mathrm{X02}$ & $\mathrm{X03}$ & X04 & $\times 05$ & $\mathrm{X06}$ & $X 07$ & Y01 & Y02 & Y03 & Y04 \\
\hline $\mathrm{X} 01$ & 1,000 & $459^{*}$ &,- 215 & $452^{*}$ & 085 & 144 & ,412 &,- 257 & 148 & 380 & 280 \\
\hline $\mathrm{X02}$ & & 1,000 &,- 239 & 203 &,- 190 & 094 &, 258 &,- 222 &, 177 &, 105 &, 036 \\
\hline $\mathrm{X} 03$ & & & 1,000 &,- 076 &,- 228 &,- 036 &,- 307 & 116 & 111 & 035 &,- 162 \\
\hline $\mathrm{X04}$ & & & & 1,000 & 018 & 147 & 315 & 045 & 189 &, 125 & 353 \\
\hline$\times 05$ & & & & & 1,000 &,- 140 & 271 & 050 & 390 &,- 306 & 144 \\
\hline $\mathrm{X06}$ & & & & & & 1,000 &, 163 & $438^{*}$ &, 243 &, 205 & 335 \\
\hline $\mathrm{X07}$ & & & & & & & 1,000 & 097 & 034 & 177 &, 350 \\
\hline Y01 & & & & & & & & 1,000 & 191 &,- 204 & 088 \\
\hline Y02 & & & & & & & & & 1,000 &,- 157 &,- 084 \\
\hline Y03 & & & & & & & & & & 1,000 & 110 \\
\hline Y04 & & & & & & & & & & & 1,000 \\
\hline
\end{tabular}

Nota. *Coeficiente de correlação de Spearman assume o valor significativo de $5 \%(p<0,05)$ entre as variáveis.

Legenda: Determinantes da estrutura de propriedade: X01: M. ADM.; X02: M. DIRET.; X03: Outros Conselheiros; X04: C.F.; X05: M. Comitê Auditoria; X06: M. Outros Comitês; X07: TAM. Variáveis do Boardlnterlocking: Y01: CEOCHAIR; Y02: R. COM 1 Grau de Parentesco; Y03: R. COM 2 Grau de Parentesco.

Fonte: Dados da pesquisa.

$\mathrm{Na}$ Tabela 4, verificam-se as correlações positivas entre os determinantes da estrutura de propriedade X01 (M. ADM) e X02 (M. DIREC.) de 0,459*, bem como da variável X01 (M. ADM.) e X04 
(C. F.) de 0,452 a um nível de significância de 5\%. Na correlação das variáveis do Board Interlocking, observa-se uma correlação positiva entre as variáveis X06 (Outros comitês) e Y01 (CEOCHAIR) de 0,438*. Nota-se que existe uma correlação baixa entre Board Interlocking e características das empresas com estrutura e controle familiar, visto que essa relação é representada apenas pela variável CEOCHAIR, ou seja, nas companhias que possuem controle do tipo familiar, a prática do Board Interlocking ocorridos com membros de diferentes setores dentro da própria companhia é recorrente. De modo geral, as empresas listadas nos níveis de governança corporativa da BM\&FBovespa, no ano de 2010, que possuem estrutura de propriedade e controle familiar, apresentam a prática do Board Interlocking pelos membros dos conselhos de administração, diretoria e demais comitês, pois ocupam cargos simultaneamente em diferentes empresas. Nota-se que, embora as empresas familiares tenham uma forma de gestão mais conservadora, essa característica pode não estar sempre atrelada aos relacionamentos de seus membros.

A partir das definições do Board Interlocking apresentadas por Mizruchi (1996), Heng e Gygax (2009) e Szalacha (2010), especula-se que companhias que possuem membros em comum com laços de parentesco (fundadores, investidores) podem ocupar cargos em conselhos de outras empresas não familiares ao mesmo tempo, visando promover interesses próprios e coletivos, podendo ser a continuidade dessas companhias, a permanência nesses cargos, ou mesmo a transferência de uma cultura menos conservadora.

Os membros de empresas familiares participarem em conselhos de outras empresas, seja na diretoria, no conselho de administração, no conselho fiscal ou como outros conselheiros, pode se apresentar como uma nova tendência do mercado. Isso implica ultrapassar as relações de parentesco, para acompanhar características mais recentes do mercado de capitais brasileiro, sinalizando práticas ambientais semelhantes e renovação dos decisores em virtude da competitividade dos mercados (Dani et al., 2013).

Do exposto e dos resultados da pesquisa, depreende-se que as companhias brasileiras pesquisadas que possuem estrutura de propriedade com controle familiar são propensas a possuírem membros de seus conselhos participando em conselhos de outras empresas, o que caracteriza a prática do Board Interlocking. Desse modo, rejeita-se a hipótese $\mathrm{H}_{0}$ : Companhias que possuem estrutura de propriedade com controle familiar não são propensas a ocorrência do Board Interlocking, o que permite aceitar a hipótese $\mathrm{H}_{1}$.

Esperava-se que em empresas familiares, em virtude da tendência de estrutura de propriedade e controle mais concentrado, não fosse significativa essa prática pelos membros diretivos. Todavia, os resultados desta pesquisa convergem com os do estudo realizado no Brasil por Santos e Silveira (2007) no que diz respeito à ocorrência da prática do Board Interlocking em companhias com conselhos de administração maiores. Destaca-se que no presente estudo foi constatado que as companhias de maior porte tendem a possuir conselhos com maior número de profissionais provenientes de outras companhias.

\section{Conclusões}

Este estudo buscou verificar a relação entre as práticas do Board Interlocking e características de empresas de estrutura de propriedade familiar com ações mais negociadas na BM\&FBovespa. Para tanto, abordam-se aspectos teóricos relacionados a estrutura de propriedade e controle, empresas familiares e prática do Board Interlocking, ressaltando a importância da temática no contexto brasileiro, bem como o papel das empresas com controle do tipo familiar, que possuem a característica principal de possuírem controle concentrado.

$\mathrm{Na}$ análise dos dados oriundos da pesquisa documental, observou-se por meio da estatística descritiva que os setores de construção e transporte e de materiais básicos foram os que apresentaram maior participação em relação ao total de empresas analisadas, com 13,04\% da amostra. Isto indica que a amostra não está concentrada em um setor específico, ao contrário, contempla diversos setores de forma relativamente equilibrada.

Outro aspecto analisado foi a participação de membros em diferentes conselhos. Constatou-se a prática do Board Interlocking em $57 \%$ das empresas da amostra, o que indica ser uma prática comum. Os membros, em sua maioria, atuam concomitantemente no conselho de administração das empresas. Mesmo que de forma menos expressiva, esta prática ocorre também com membros dos cargos de diretoria, outros conselheiros e conselho fiscal.

Um mapeamento das empresas interligadas em 2011 foi realizado devido a membros em comum. Verificou-se que a maioria das relações entre os conselhos é estabelecida por um membro 
Relação entre as práticas do board interlocking e características de empresas de estrutura de propriedade familiar com ações mais negociadas na BM\&FBOVESPA

em comum, e que há predominância da atuação dos membros em apenas duas empresas, embora haja empresas com maior presença de membros simultaneamente, como é o caso das empresas MMX e MPX, em que há participação de quatro membros em comum.

Constatou-se também a ocorrência de relação de parentesco entre os membros do conselho e a direção das empresas analisadas. Por se tratar de empresas com controle familiar, denota-se que as características familiares transpassam a estrutura de propriedade, e que ocorre predominância de relações de parentesco de $1^{\circ} \mathrm{grau}$ nas empresas da amostra.

Por fim, verificou-se a relação entre os conjuntos de variáveis delineadas para análise, por meio de correlação. Os valores demonstram relação entre algumas das variáveis analisadas, isto é, há relação em nível baixo entre o Board Interlocking e características das empresas com estrutura e controle familiar.Conclui-se que nas empresas de estrutura de propriedade familiar pesquisadas, classificadas entre as 100 maiores empresas listadas nos níveis de governança corporativa da BM\&FBovespa, verifica-se a prática do Board Interlocking pelos membros do conselho de administração, diretoria e conselho fiscal. Tal decorre do fato de membros de uma empresa ocuparem cargos simultaneamente em outras empresas, mesmo com características de empresas de propriedade e controle familiar.

Os resultados reforçam a ideia de que companhias de maior porte tendem a possuir conselhos com mais profissionais provenientes de outras companhias, conforme constatado na pesquisa de Santos e Silveira (2007). Os achados da pesquisa sugerem ainda a existência de fluxos de informação entre estas empresas, conforme preconizado por Szalacha (2010). Esperava-se que em empresas familiares, devido a tendência de capital e controle mais concentrado, não fosse significativa a prática do Board Interlocking pelos membros diretivos.

Com base nos resultados da pesquisa rejeita-se a hipótese $H_{0}$, de que companhias que possuem estrutura de propriedade com controle familiar não são propensas a ocorrência do board interlocking, e desta forma, aceita a $\mathrm{H}_{1}$. Confirma-se, assim, que o Board Interlocking é uma prática comum dos membros dos conselhos de administração, diretoria e demais comitês das empresas familiares brasileiras pesquisadas. No entanto, os resultados desta pesquisa não podem ser extrapolados para além da amostra pesquisa e estão limitados a estratégia e procedimentos de pesquisa adotados neste estudo.

Os resultados da pesquisa, se de um lado não coadunam com o esperado, de outro sinalizam a configuração de aspectos relevantes para a caracterização e desenvolvimento do mercado de capitais brasileiro, além de inspirar novas pesquisas sobre o tema. Recomenda-se que em futuras pesquisas seja realizada uma comparação entre empresas que possuem estrutura de propriedade com controle concentrado e pulverizado, por estas possuírem características diferenciadas. Além disso, seria interessante relacionar outros fatores à prática do Board Interlocking, no sentido de buscar explicações para essa prática nas empresas.

\section{Referências}

Allen, M.P. (1974). The structure of interorganizational elite cooptation: interlocking corporate directorates. American Sociological Review, 39(3), 393-406.

Anderson, R., \& Reeb, D.M. (2004). Founding-family ownership and firm performance: evidence from the S\&P 500. The Journal of Finance, 58(3), 1301-1328.

Berle, A.A., \& Means, G.C. (1984). A moderna sociedade anônima e a propriedade privada. São Paulo: Abril Cultural. 335p.

Beuren, I.M., \& Muller, E.T.C. (2010). Evidências de institucionalização da controladoria em empresas familiares. Revista de Administração FACES Journal, 9(2), 43-63.

Beuren, I.M., Dani, A.C., Dal Vesco, D.G., \& Krespi, N.T. (2013). Redes Sociais na estrutura de capital das empresas de serviço de utilidade pública e de telecomunicações. Revista Alcance, 20(3), 309324.

Boff, M.L., Beuren, I.M., \& Hein, N. (2009). Informações recomendadas pelo Parecer de Orientação $n^{\circ}$. 15/87 da CVM no Relatório da Administração de empresas familiares de capital aberto. BASE Revista de Administração e Contabilidade Unisinos, 6(3), 247-257.

Dami, A.B.T., Rogers, P., \& Ribeiro, K.C.S. (2007). Estrutura de propriedade no Brasil: evidências empíricas no grau de concepção acionária. Revista Contemporânea de Economia e Gestão, 5(2), 21- 
30.

Dani, A.C., Beck, F.; Almeida-Santos, P.S., \& Lavarda, C.E.F. (2013). Análise da estrutura de propriedade das empresas listadas no ISE por meio da aplicação de Redes Sociais. Revista de Educação e Pesquisa em Contabilidade, 7(3), 240-258.

Demsetz, H., \& Lehn, K. (1985). The structure of corporate ownership: causes and consequences. Journal of Political Economy, 93(6), 1155-1177.

Drago, C., Millo, F., Ricciuti, R., \& Santella, P. (2011). Corporate governance reforms, interlocking directorship networks and company value in Italy (1998-2007). CESIFO Working Paper no. 3322. Category 11: Industrial Organization. Recuperado em 15 outubro, 2011, de http://papers.ssrn.com/sol3/papers.cfm?abstract_id $=1756575$

Dooley, P.C. (1969). The interlocking directorate. American Economic Rewiew, 29(3), 314-323.

Fich, E.M., \& White L.J. (2005). Why do CEO reciprocally sit on each other's Board. Journal of Corporate Finance, 11 (1), 175-195.

Fich, E.M., \& Shivdasani, A. (2006). Are busy boards effective monitors? The fournal of Finance, $61(2), 689-724$.

Gil, A.C. (2010). Como elaborar projetos de pesquisa. 5 ed. São Paulo: Atlas. 184p.

Gomes, J.A., Sousa Neto, J.A., \& Martins, H.C. (2006). O Conselho de Administração em empresas familiares: avaliação da adesão ao Código de Melhores Práticas do Instituto Brasileiro de Governança Corporativa. Anais do Encontro Nacional da Associação Nacional de Pós-Graduação e Pesquisa em Administração, Salvador, BA, Brasil, 30.

Heng, L.W., \& Gygax, A. (2009). Board interlocking network and the design of executive compensation packages. Recuperado em 05 outubro, 2011, de http://ssrn.com/abstract=965991

Instituto Brasileiro de Governança Corporativa (IBGC). Código das melhores práticas de governança corporativa. 4. ed. Recuperado em 15 outubro, 2011, de http://www.ibgc.org.br/CodigoMelhoresPraticas.aspx

Jaggi, B., Leung, S., \& Gul, F. (2009). Family control, board independence and earnings management: Evidence based on Hong Kong firms. J. Account. Public Policy, 28, 82-300.

Jensen, M.C., \& Meckling, W.H. (1976). Theory of the firm: managerial behavior, agency costs and ownership structure. Journal of Financial Economics, 3(4), 305-360.

Kang, D.L., \& Sorensen, A.B. (1999). Ownership organization and firm performance. Annual Review of Sociology, 25(1), 121-144.

La Porta, R., Lopez-de-Silanes, F., Shleifer, A., \& Vishny, R. W. (1998). Law and finance. Journal of Political Economy, 106(6), 1113-1155.

La Porta, R., Lopez-de-Silanes, F., \& Shleifer, A. (1999). Corporate ownership around the world. The Journal of Finance, 54(2), 471-517.

Leal, R.P.C., Silva, A.L.C., \& Valadares, S.M. (2002). Estrutura de controle das companhias brasileiras de capital aberto. RAC. Revista de Administração Contemporânea, 6(1), 7-18.

Lodi, J. B. (1998). A Empresa Familiar. São Paulo: Pioneira.

Marra, A., Mazzola, P., \& Prencipe, A. (2011). Board Monitoring and Earnings Management Pre- and Post-IFRS. The International Accounting, 46(4), 205-230.

Mendes-da-Silva, W. (2010) Board interlocking, desempenho financeiro e valor das empresas brasileiras listadas em bolsa: análise sob a ótica da teoria dos grafos e de redes sociais. Tese de Doutorado, Universidade de São Paulo, São Paulo, SP, Brasil. 254p.

Mendes-da-Silva, W., \& Grzybovski, D. (2006). Efeitos da governança corporativa e da performance empresarial sobre o turnover de executivos no Brasil: comparando empresas familiares e não familiares. Revista de Administração Mackenzie, 7(1), 45-70.

Mendes-da-Silva, W., Rossoni, L., Martin, D.M.L., \& Martelanc, R. (2008). A influência das redes de relações corporativas no desempenho das empresas do novo mercado da Bovespa. Anais do Encontro Nacional da Associação Nacional de Pós-Graduação e Pesquisa em Administração, Rio de Janeiro, RJ, Brasil, 32. 
Mendes-da-Silva, W., \& Vidal, P. G. (2010). Lost in space? The topography of social relationship network of board members in the Brazilian capital market. Encontro Brasileiro de Finanças, São Paulo, SP, Brasil, 10. Recuperado em 10 setembro, 2011, dehttp://bibliotecadigital.fgv.br/ocs/index.php/ebf/10EBF/paper/viewFile/1159/974

Mizruchi, M.S. (1996). What do interlocks do? An analysis, critique, and assessment of research on interlocking directorates. Annual Review of Sociology, 22(1), 271-298.

Non, M. C., \& Franses, P.H. (2007) Interlocking boards and firm performance: evidence from a new panel database. Tinbergen Institute Discussion Paper No. 07-034/2. Recuperado em 10 setembro, 2011, de http://papers.ssrn.com/sol3/papers.cfm?abstract_id=978189

Richardson, R.J. (1999). Pesquisa social: métodos e técnicas. 3 ed. São Paulo: Atlas. 286p.

Santos, R.L., \& Silveira, A.D.M. (2007). Board Interlocking no Brasil: a participação de conselheiros em múltiplas companhias e seu efeito sobre o valor das empresas. Revista Brasileira de Finanças, $5(2), 125-163$

Sarlo Neto, A., Lopes, B., \& Dalmácio, F.Z. (2009). A influência da estrutura de propriedade sobre a informalidade dos lucros contábeis divulgados pelas empresas negociadas na Bovespa. Anais do Encontro Nacional da Associação Nacional de Pós-Graduação e Pesquisa em Administração, Rio de Janeiro, RJ, Brasil, 33.

Siffert Filho, N.F. (1998). Governança corporativa: padrões internacionais e evidências empíricas no Brasil nos anos 90. Revista do BNDES, 5(9).

Stuart, T E., \& Yim, S. (2010). Board interlocks and the propensity to be targeted in private equity transaction. Journal of Financial Economics, 97(1), 174-189.

Szalacha, J. (2010). Interlocking directorates and possible conflict of interests. Working Paper Conference. Conflict of interest in Central and Eastern Europe. UMK Toruń, 2010. Recuperado em 05 outubro, 2011, de http://www.coi.conference.umk.pl/texts/Szalacha.pdf

Torres, D., Bruni, A.L., Rivera-Castro, M.A., \& Martinez, A.L. (2010). Estrutura de propriedade e controle, governança corporativa e o alisamento de resultados no Brasil. Revista Contemporânea de Contabilidade, 7(13), 11-34.

Vergara, S.C. (1998). Projetos e relatórios de pesquisa em administração. (2a ed.). São Paulo: Atlas. 90p.

Welsh, D. H. B. \& Raven, P. (2006). Family Business in the Middle East: An Exploratory Study of Retail Management in Kuwait and Lebanon. Family Business Review, 19(1), 29-48. 